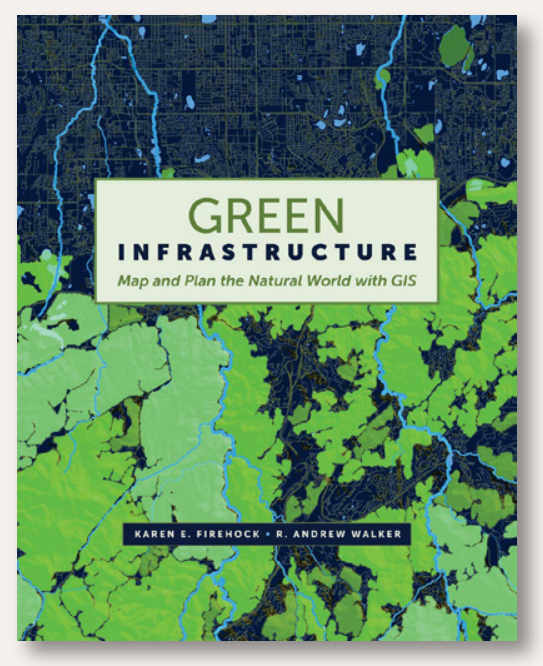

\title{
GREEN INFRASTRUCTURE: MAP AND PLAN THE NATURAL WORLD WITH GIS
}

\author{
By Karen E. Firehock and R. Andrew Walker
}

Esri Press, 2019

282 pages

Softcover: $\$ 49.99$, ISBN 978-1-58948-486-3

Review by: Yanning Wei, University of Connecticut

Even though Green Infrastructure (GI) is definitely not a newly arrived concept, it is commonly oversimplified by laypersons and even some planning practitioners as merely adding plants to our cities: green roofs, rooftop gardens, tree-lined roads or streets, rain gardens, home gardens, and the like. The authors of Green Infrastructure: Map and Plan the Natural World with GIS-Firehock and Walker, an environmental planner and GIS practitioner, respectively—remind readers that GI is not just a collection of greenish elements, but instead represents a coherent and systematic approach to building and maintaining a livable and sustainable urban environment. Drawing on the germinal work of Ian McHarg (1995) and utilizing their own hands-on experience from years of work in environmental planning, community design, and GIS, the authors call for implementing McHarg's ideas about "Designing with Nature" to build GI as a means of tackling the pressing environmental issues we face such as water quality degredation, urban flooding, shoreline erosion, and habitat loss.

Maps and spatial data play a unique and indispensable role, alongside a plethora of other components, in the process of environmental planning, and the authors suggest that "by identifying and integrating a network of critical landscapes" using spatial data management, "communities can protect the places and resources that help people, wildlife, and economies thrive" (1). This book is about modeling "critical landscapes" using GIS, with the goal of replacing the conventional "gray infrastructure" with a green one, and in its eight chapters the reader learns how to design with nature by mapping landscapes and managing data.

The first chapter introduces what GI is, why it matters, and the theory and practice of GI planning. It also provides readers with a brief history of GI planning in several parts of the world, including the United States, Japan, and the European Union. The second chapter deals with the conceptual design of a GI model, and the major design components that should be considered. The chapter highlights effective ways of modeling connectivity among such key conceptual landscape elements as core, edge, corridor, and so forth. With Chapter Three, "The six-step process," the focus of the book shifts to the technical details of GI planning: how to actually create a GI plan with GIS. This chapter is a bullet-point outline for creating a GI model, with six key steps: setting goals, reviewing data, making asset maps, assessing risks, determining opportunities, and implementing the plan. This chapter provides readers with a practical framework for planning GI, and the essential strategic actions required to carry the plan out.

Technical specifics regarding relevant data are found in Chapter Four, "Getting the right data," which dives deeply into the details of spatial data acquisition. It provides readers with a detailed list of key spatial features to be included-in particular, local natural and cultural assets such as water resources, forestry, parks and recreation areas, and historic and cultural heritage sites. With the completion 
of this phase, the datasets are ready to be integrated and mapped in a GIS.

Chapter Five, "Making asset maps," is pleasingly filled with a number of colorful images and maps, and is rich in technical details. It tells about how to make thematic maps and how to use them to identify connectivity among the key elements of GI. Next, Chapter Six describes how to use GIS to evaluate and reveal risks to natural and cultural assets. Starting with an outline of the major types of risk, both natural and human-made, the chapter presents a comprehensive introduction to the methods that could be used by planners to evaluate and deal with location-specific risks.

Completion of the mapmaking stage is not the end of GI planning, and in Chapter Seven, "Determining opportunities," the authors discuss the importance of also planning for risks, potential damages, and possible mitigating actions that may need to be taken. In addition, they emphasize that a GI planner's task is identifying opportunities even in scenarios not commonly considered environmentally friendly, such as plans for new transportation systems or for landfills and dumps.

"Implementing GI plans" is the last chapter, and, as the title suggests, is about implementation of the plans discussed in the previous chapters-what to tackle, who does what, and how to go about it. The authors strongly suggest that the effective use of maps to support GI-related decision-making processes is critically important to any implementation.

The book includes three appendices: one on the history of the landscape connectivity theory of modeling, another on technical specifics regarding spatial data modeling, and a third with some useful online sources.

Conventional "gray infrastructure" planning is based on the postulation of a fundamental human/nature dichotomy and a corollary view of humanity as the conqueror of nature, but Green Infrastructure presents an alternative wherein humans are an integral part of the natural system instead of an adversarial manipulator of it. The authors remind us that while Earth can continue to exist without humans, humans cannot survive without a healthy Earth—not even for a very short time-so we need to adopt a workable plan to keep the Earth healthy. We should, as Ian McHarg famously put it, "abandon the self-mutilation" and "must design with nature" (quoted in Fleming, et al. 2019) and this is because, with no place else to go, we have no other options available. Thus, the authors suggest, we need GI planning and practice to make the world a better place to live. They further suggest that we have to know how the environment works as a complicated, dynamic system before we can make better plans for a sustainable future.

It is true that GI planning is much more than just planting trees, greening roofs, and announcing new nature reserves. For example, it has come to light that the flawed infrastructure planning in and around the city of Houston, Texas, was partially responsible for the enormous environmental and economic loss the city suffered during the devastating 2017 hurricane season (Campoy and Yanofsky 2017). Put simply, when new homes and other buildings are built on the floodplains of natural waterways, it is not hard to predict what will happen when natural hazards like hurricanes strike-despite any number of greenroofed buildings, rain gardens, and tree-lined neighborhoods. This book suggests that we urgently need more data, and more data-driven systematic insights, in order to build a better understanding of the environment and our relationship with it.

The main body of the book, Chapters Four through Eight, can be seen as a useful and convenient cookbook showing how GIS and spatial models can be used to simulate the real-world environment, manage spatial data, and help make critical decisions. While GI planning can, no doubt, be conducted without GIS software, GIS is, in many ways, an ideal platform for environmental modeling and sustainability studies. The environmental movement in the 1960s was, in fact, a significant driver for the development of GIS as a technology, and, by extension, for the founding of Esri (originally known as Environmental Systems Research Institute). One could say that GIS was born for modeling the environment, and its superb capability of modeling features on the surface of the Earth through the layering of complex spatial data has made it a popular tool among environmental planning practitioners since its birth (Fleming et al. 2019).

One potential drawback to a conventional GIS approach to any question is the tendency to reduce everything to quantitative terms. Enumerated quantities are, after all, what computers handle best, and the ability to find correlations by overlaying spatial data sets is one of the great strengths 
of GIS. These very strengths also lend themselves to oversimplification, a tendency promoted by stories told to the young-like that of John Snow's identification, by means of simple data overlays, of a single source point for an 1854 cholera outbreak.

In contrast to this, one of the strengths of this book lies in its effort to strike a balance between holistic and reductionist perspectives. For example, the authors of Green Infrastructure stress the value of local knowledge and the vital, "driving force" (95) role of community support-factors hard to quantify or digitize as geographic featuresright alongside spatial data modeling and data acquisition. Yes, there is a heavy emphasis on the technical specifics of using GIS tools, but the reader is constantly reminded that GI planning is about sustainable community development—and that tools are just a means of getting there.

The only vital piece missing from this book, from my perspective, is a discussion of how GIS can be used as a tool to mobilize local communities and get people engaged in the process of GI planning.

Overall, this book is exactly what the authors tell us they intended it to be: an excellent reference for anyone who cares about the environment and sustainable development, and who wants to use GIS applications to help achieve their goals in these fields. The authors deliberately avoid jargon, and the chapters are written in plain language. Readers who are not GIS professionals can skip the technical parts, but those parts will be of great importance and value to those who can profit from them.
This book also can serve as an excellent reference book for intermediate and advanced GIS courses. As an educator myself, I have, over the past two decades, noticed that it can sometimes be quite hard for some students, even with several courses under their belts, to come to grips with complex assignments involving spatial modeling or database management, let alone conceptualize the potential for what GIS can do. I believe that Green Infrastructure: Map and Plan the Natural World with GIS can, if used properly, help anyone to understand both the GI planning challenge, and the challenges of better using GIS tools.

\section{REFERENCES}

Campoy, Ana, and David Yanofsky. 2017. “Houston's Flooding Shows What Happens When You Ignore Science And Let Developers Run Rampant." Quartz. Accessed February 3, 2020. https://qz.com/1064364/ hurricane-harvey-houstons-flooding-made-worseby-unchecked-urban-development-and-wetlanddestruction.

Fleming, William, Frederick Steiner, William Whitaker, Karen M'Closkey, and Richard Weller. 2019. "How Ian McHarg Taught Generations to 'Design With Nature.” CityLab. Accessed February 3, 2020. https:// www.bloomberg.com/news/articles/2019-06-10/ the-legacy-of-design-with-nature-50-years-later.

McHarg, Ian L. 1995. Design with Nature, 25th Edition. New York: J. Wiley. 